\title{
Realities of Reflective Practice Skill among Public Health Nurses in Japan and Related Learning and Lifestyle Factors
}

\author{
Reiko Okamoto', Keiko Koide², Yuki Maura3 ${ }^{3}$ Miho Tanaka4 \\ ${ }^{1}$ Division of Health Sciences, Graduate School of Medicine, Osaka University, Osaka, Japan \\ ${ }^{2}$ Faculty of Education, Shitennoji University, Osaka, Japan \\ ${ }^{3}$ Faculty of Nursing and Rehabilitation, Konan Women's University, Hyogo, Japan \\ ${ }^{4}$ Sakai City North Health Center, Sakai City, Japan \\ Email: reiko@sahs.med.osaka-u.ac.jp
}

How to cite this paper: Okamoto, R., Koide, K., Maura, Y. and Tanaka, M. (2017) Realities of Reflective Practice Skill among Public Health Nurses in Japan and Related Learning and Lifestyle Factors. Open Journal of Nursing, 7, 513-523. https://doi.org/10.4236/ojn.2017.75040

Received: April 3, 2017

Accepted: May 15, 2017

Published: May 18, 2017

Copyright $\odot 2017$ by authors and Scientific Research Publishing Inc.

This work is licensed under the Creative Commons Attribution International License (CC BY 4.0).

http://creativecommons.org/licenses/by/4.0/

\begin{abstract}
Background: According to the diversification of the health needs and the expansion of health disparities, it is necessary to raise their reflective practice skills so that PHNs present more appropriate activities. The purpose of this study was to elucidate the realities of reflective practice skills among public health nurses in Japan and identify related factors. Methods: This study covered 1725 public health nurses in the Chugoku/Shikoku area. We conducted an anonymous self-completed questionnaire survey. As reflective practice skills (RPS), we adopted the six components of the six cycles of the Gibbs reflective model. We used the 20 criteria of the Scale for Practical Competence (SPC). We set 25 learning history/daily lifestyle items. The study plan was approved by the Ethics Committee of Okayama University. Results: We analyzed the 962 (55.8\%) valid responses. Although years of experience as a public health nurse was highly correlated with practical skills as measured by SPC, with a correlation coefficient of 0.627 , it was not closely related with RPS, with a correlation coefficient as low as 0.129 . A logistic regression analysis of the eight learning history items and six daily lifestyle items associated with RPS, with the introduction of the high/low RPS groups as dependent variables, showed a convergence to five factors (odds ratio of 1.38 - 2.29). Conclusions: Going forward, we will need to consider how to accumulate learning on a daily basis and how to include positive health practice in PHN education, in connection with exploring the curriculum and method of training.
\end{abstract}

\section{Keywords}

Reflective Practice, Public Health Nursing, Education, Skill, Related Factors 


\section{Introduction}

Reflective practice is a forward-looking exercise for practitioners to review their own way of working and find out about the best practice expected of them [1]. It is essential that nurses are able to reflect on their practice to find better ways, if they are to improve their practical skills [2]. The value of reflection lies in inspiring practitioners to generate something that leads to a more constructive process, particularly in uncertain conditions that preclude any easy answer [2].

Public health nurses are working to find solutions or improvements to community health issues. Health issues, however, change with the times, constantly influenced by area characteristics and the social landscape. Thus, there is no correct answer in the activities of public health nurses, who are always required to find the best possible solution to each specific case. This means that public health nurses have to upgrade their reflective practice skill if they are to ensure quality services. This is particularly important because of the realities of society today, characterized by the diversification of health issues, widening health gaps and frequent health crises including natural disasters and emerging infections.

Although reflection has been integrated into nursing education in Japan [3], it has yet to be widely adopted in public health nursing education. Previous studies only examined the effectiveness of lifestyle counseling skill development programs for public health nurses that used reflective practice [4]. Public health nurses have opportunities for reflection in their day-to-day activities as they report on and record the results of home visits and health services. However, such reflection stays within the limits of keeping their daily work journals, and does not cover their own practice. In order to improve the quality of public health nursing activities in Japan, it is thus necessary to identify the current levels of reflective practice skill among public health nurses and use the results to develop a training curriculum and system for skill upgrading.

The purpose of this study was to elucidate the realities of reflective practice skill among public health nurses in Japan and identify related factors. Since it is said that reflection stems from experience and that any learning should be built upon daily first-hand experiences [5], this study focused on the learning experience and daily lifestyle of individuals. The significance of this study lies in the development of basic materials to consider how education should serve to upgrade reflective practice skill.

\section{Study Approach}

\subsection{Study Design}

The present study was designed as a cross-sectional field survey and relation exploration research.

\subsection{Coverage of Study}

This study covered 1725 public health nurses, or half of the Japanese public health nurses affiliated with the nine prefectures in the Chugoku/Shikoku area and all municipalities located in the prefectures. 


\subsection{Survey Method}

We conducted an anonymous self-completed questionnaire survey. We sent a set of request letters, ethical consideration statements, questionnaire forms and reply envelopes to the lead public health nurse of each municipality, who was asked to distribute the survey kits to half of the full-time public health nurses selected to represent all age groups without bias. The survey was conducted from December 2013 to January 2014 in Chugoku, and from December 2014 to January 2015 in Shikoku.

\subsection{Scope of Survey}

(1) Basic attributes

Basic attributes included gender, age, years of PHN experience and place of work.

(2) Realities of reflective practice skill

We defined reflective practice skill as comprising the six components of the six cycles of the Gibbs reflective model [6], including description ("What happened?"), feelings ("What were you thinking and feeling?"), evaluation ("What was good and bad about the experience?"), analysis ("What sense can you make of the situation?"), conclusion ("What else could you have done?") and action plan ("If it arose again what would you do?"). Regarding each of the components, a question was asked to see if their practice involved writing. We thought that the responses would be relevant because this model is used widely across the globe. Specifically, we asked to what extent the following statements applied to the respondent's core activities:

1) I always write down, and check what I did and why I did it.

2) I always write down, and recall what I thought and felt about what I did.

3) I always write down, and evaluate what was good and bad about what I did.

4) I always write down, and analyze what sense I could make of what I did.

5) I always write down what things I could have done better to help improve my performance.

6) I always write down what I would do if the same situation arose gain.

Regarding each of those statements, the respondents were asked to reply on a scale of 1 to 6: "Does not apply at all" (1); "Does not apply" (2); "Somewhat does not apply" (3); "Somewhat applies" (4); "Applies" (5); and "Applies very much" (6). Before analyzing the result, we calculated Cronbach's alpha for the six reflective practice skill (hereafter "RPS") components. The coefficient turned out to be 0.935 , indicating a high internal consistency that warrants using the aggregate score for analysis.

Since it has been verified that the practical skills of public health nurses improve with experience [7] [8], we used the 20 criteria (score ranging from 20 to 80 points) of the Scale for Practical Competence (hereafter "SPC") of Public Health Nurses for measuring the practical skills of the PHNs [9], in order to find if the same is true with RPS. We adopted the questions and assessment measures in the original version of SPC, in view of its established reliability and relevance. 
(3) Learning history and daily lifestyle items

We set nine items in total for learning history: PHN training institution; level of education; place of work (overlap with attributes); experience in presentation at academic meetings; average amount of annual out-of-pocket investment in self-development; out-of-pocket subscription to any journal for the current year; experience in reading any specialized book over the past year; membership of any professional association for the current year; and participation in any training or study session over the past year.

We set a total of 16 items regarding daily lifestyle: 10 daily health practice items integrating Breslow's seven items [10] and Morimoto's eight items [11] (with five overlapping items); and six positive health practice items determined through consultations among the researchers.

\subsection{Method of Analysis}

(1) Realities of reflective practice skills

We calculated the total RPS score, and mean and standard deviation of the six components. We also conducted a correlation analysis between the years of PHN experience on one hand, and SPC and RPS on the other for comparison purposes.

(2) Learning and lifestyle factors related to reflective practice skill

Using the mean value as borderline, we classified the respondents into the high RPS and low RPS groups for cross tabulation with learning and lifestyle items, followed by a statistical test ( $\chi^{2}$ test) at the significance level of $5 \%$. Afterwards we performed a logistic-regression analysis of the learning and lifestyle items associated with RPS as independent variables, with the introduction of the high/low RPS groups as dependent variables.

We used SPSS Statistics 22 for the analysis.

\subsection{Ethical Considerations}

We provided to the lead PHNs and potential participants written explanations on ethical considerations, including the freedom (not) to participate in the survey, the protection of personal information, the method of data storage, the publication of the findings and the cost of participating in the survey, among others. Individual participants were asked to mail the completed questionnaire form for collection, and the return of the questionnaire form was regarded as indicating consent on the part of the participant. The study plan was approved by the Ethics Committee for Nursing Study, Graduate School of Health Sciences, Okayama University (approval no. M13-02, 29 October 2013).

\section{Results}

\subsection{Collection}

Of the 982 (56.9\%) questionnaire forms returned, we analyzed the 962 (55.8\%) valid responses. The attributes of the respondents are shown in Table 1 . The 
Table 1. Attribute $(\mathrm{N}=962)$.

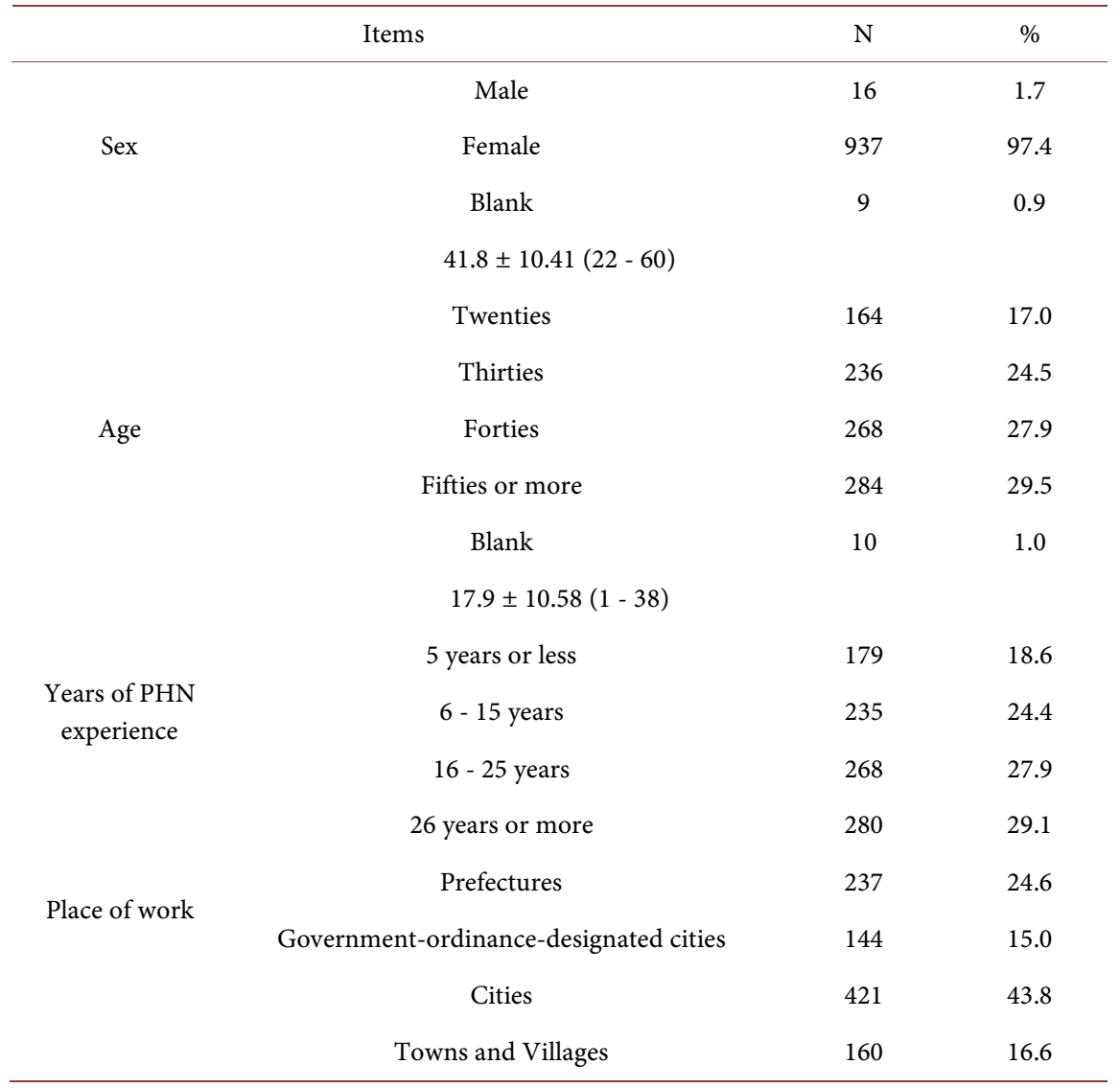

Mean value \pm standard deviation (range) for age and years of PHN experience (except where data are not available).

respondents were mostly females, aged 41.8 on average, ranging from 22 to 60 , but each age bracket had over 100 respondents.

\subsection{Realities of Reflective Practice Skill}

The mean value \pm standard deviation (median, range) of RPS was $20.8 \pm 5.81$ $(21,6$ - 36). As regards the six components, the value stood at $3.8 \pm 1.15(4,1-$ 6), $3.5 \pm 1.12(4,1-6), 3.4 \pm 1.10(4,1-6), 3.3 \pm 1.08(3,1-6), 3.4 \pm 1.13(3,1-$ $6)$ and $3.3 \pm 1.12(3,1-6)$, respectively.

Although years of PHN experience was highly correlated with practical skills as measured by SPC, with a correlation coefficient of 0.627 , it was not closely related with RPS, with a correlation coefficient as low as 0.129 (Table 2, Figure 1 and Figure 2).

\subsection{Learning and Lifestyle Factors Related to Reflective Practice Skill}

Eight learning history items had a significant relationship with the two RPS groups $(p<0.05)$, including PHN training institution, level of education, place of work, experience in presentation at academic meetings, average amount of annual out-of-pocket investment in self-development, out-of-pocket subscrip- 


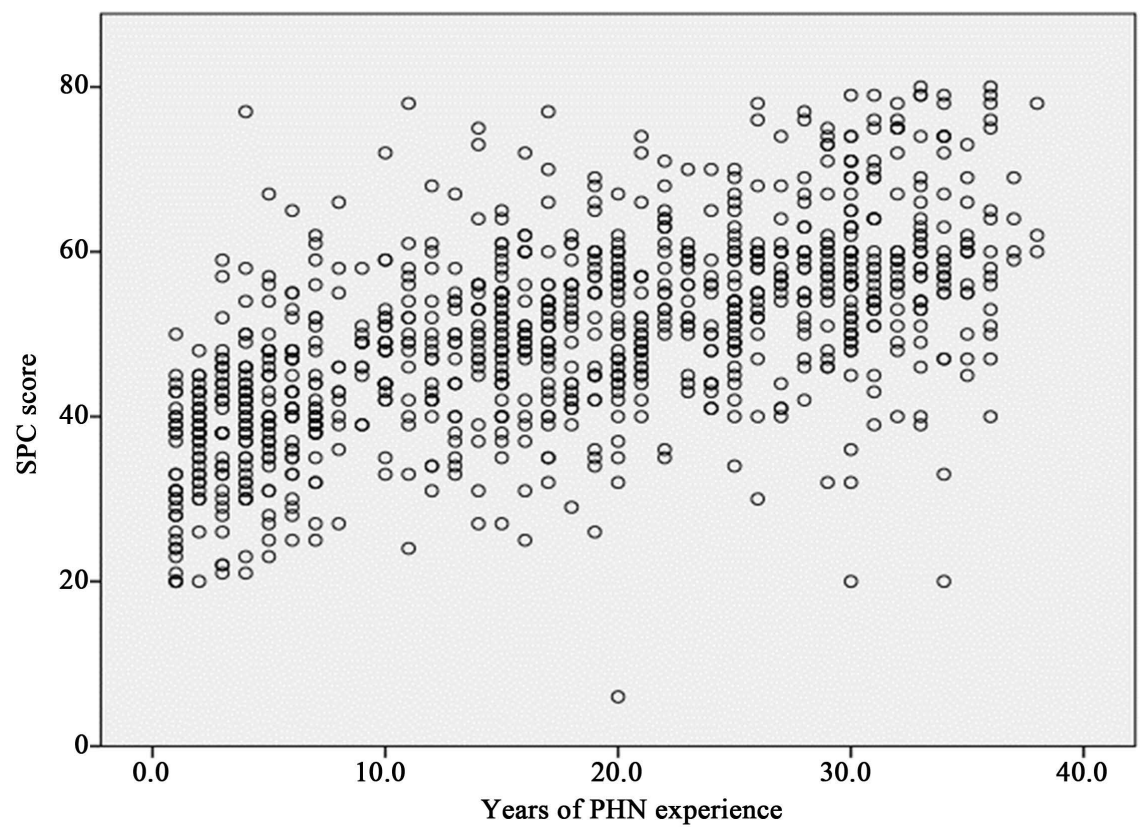

Figure 1. Correlation between practical competence of public health nurses and years of experience.

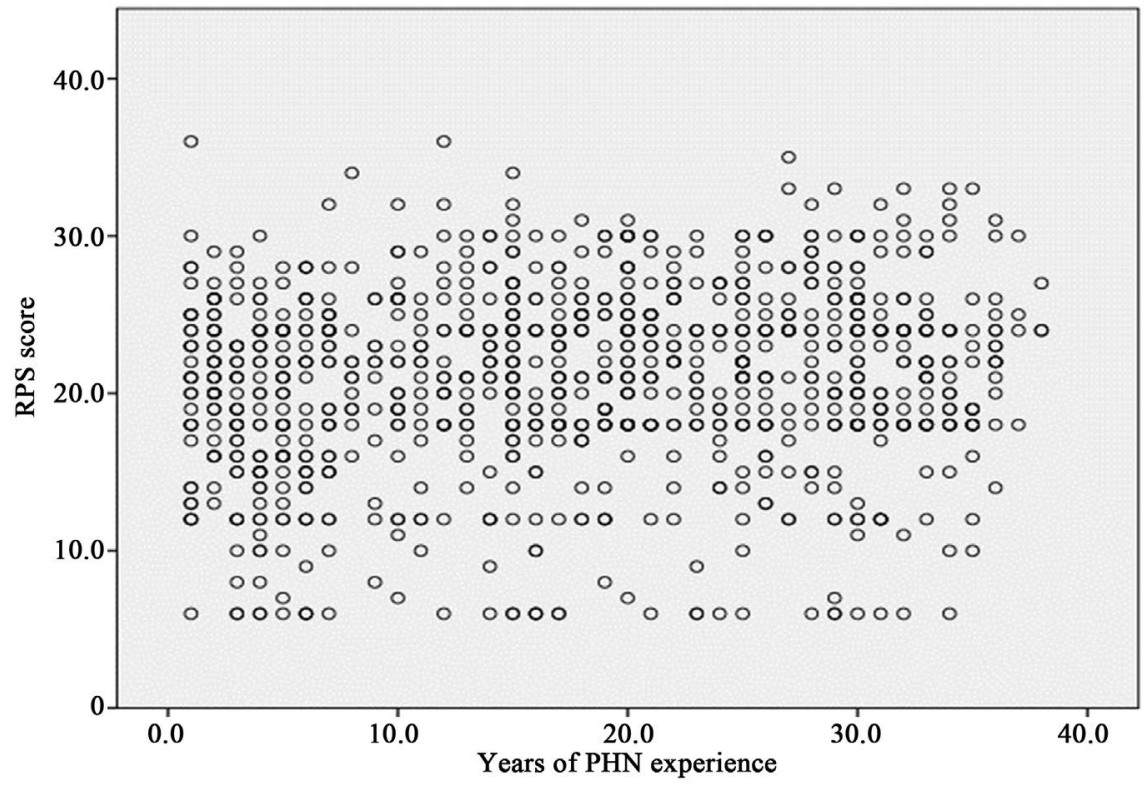

Figure 2. Correlation between reflective practice skill of public health nurses and years of experience.

Table 2. Correlation between practical competence/reflective practice skill of public health nurses and years of experience.

\begin{tabular}{ccc}
\hline & $\begin{array}{c}\text { Correlation coefficient } \\
\text { with SPC score }\end{array}$ & $\begin{array}{c}\text { Correlation coefficient } \\
\text { with RPS score }\end{array}$ \\
\hline Years of PHN experience & $0.627^{* *}$ & $0.129^{* *}$ \\
Correlation coefficient represents spearman's rho (two-tailed).
\end{tabular}

$P<0.01^{* *}$ 
tion to any journal for the current year, experience in reading any specialized book over the past year and membership of any professional association for the current year. For each of those items, the share of the high RPS group exceeded that of the low RSP group by at least one percentage point among those who gave the following answers to the questions, respectively: One-year vocational school or specialized junior college course; Vocational school or specialized junior college; Prefectures; Yes; Yes; Yes; Yes; and Yes (Table 3).

Likewise, some daily lifestyle items had a significant relationship with the two RPS groups, including one daily health practice item (i.e. "Balanced diet") and five positive health practice items (i.e. "Active in adopting useful health information in daily lifestyle", "Usually cook food for myself and my family", "Try consciously to walk and use stairs", "Always take care not to catch a cold" and "Remain sociable with enjoyment"). The respondents giving those answers were likely to be included in the high RPS group (Table 3).

Further, a logistic regression analysis (step-up procedures, stepwise, likelihood ratio) of the eight learning history items and six daily lifestyle items associated with RPS, with the introduction of the high/low RPS groups as dependent variables and years of PHN experience as moderator variable, showed a convergence to the five items listed in Table 4. Thus, the factors related to the high RSP group were found to be: "Remain sociable with enjoyment/Yes (odds ratio of 2.290)"; "Active in adopting useful health information in daily lifestyle/Yes (2.148)"; "Experience in presentation at academic meetings/Yes (1.634)"; "Experience in reading any specialized book/Yes (1.470)"; and "PHN training institution/One-year vocational school or junior college course (1.380)".

\section{Discussion}

\subsection{Representation of Population}

There is no problem in the representation of the population, about a quarter of which was covered by the survey without any bias in age or place of work.

\subsection{Realities and Characteristics of Reflective Practice Skill}

(1) Difficulties in process leading to action plan

The mean score for each of the six RPS components stood at over 3, just between "4. Somewhat applies" and "3. Somewhat does not apply". The median score was 4 for "description", "feelings", and "evaluation", but only reached 3 for "analysis", "conclusion" and "action plan", thus pointing to a lower skill level in the latter half of reflection, i.e. skill to make sense out of experience for forward-looking purposes. This indicates that the practice of running the whole reflection cycle to action planning, as per the Gibbs reflective model, has not been established among Japanese public health nurses.

(2) RPS without any correlation with experience as PHN

Although our correlation analysis indicated a strong correlation between the practical skills of public health nurses in general and the years of PHN experience, as with previous studies, we found that RPS had little to do with the years 
Table 3. Relationships between learning and lifestyle factors of public health nurses and reflective practice skill scores $(\mathrm{N}=962)$.

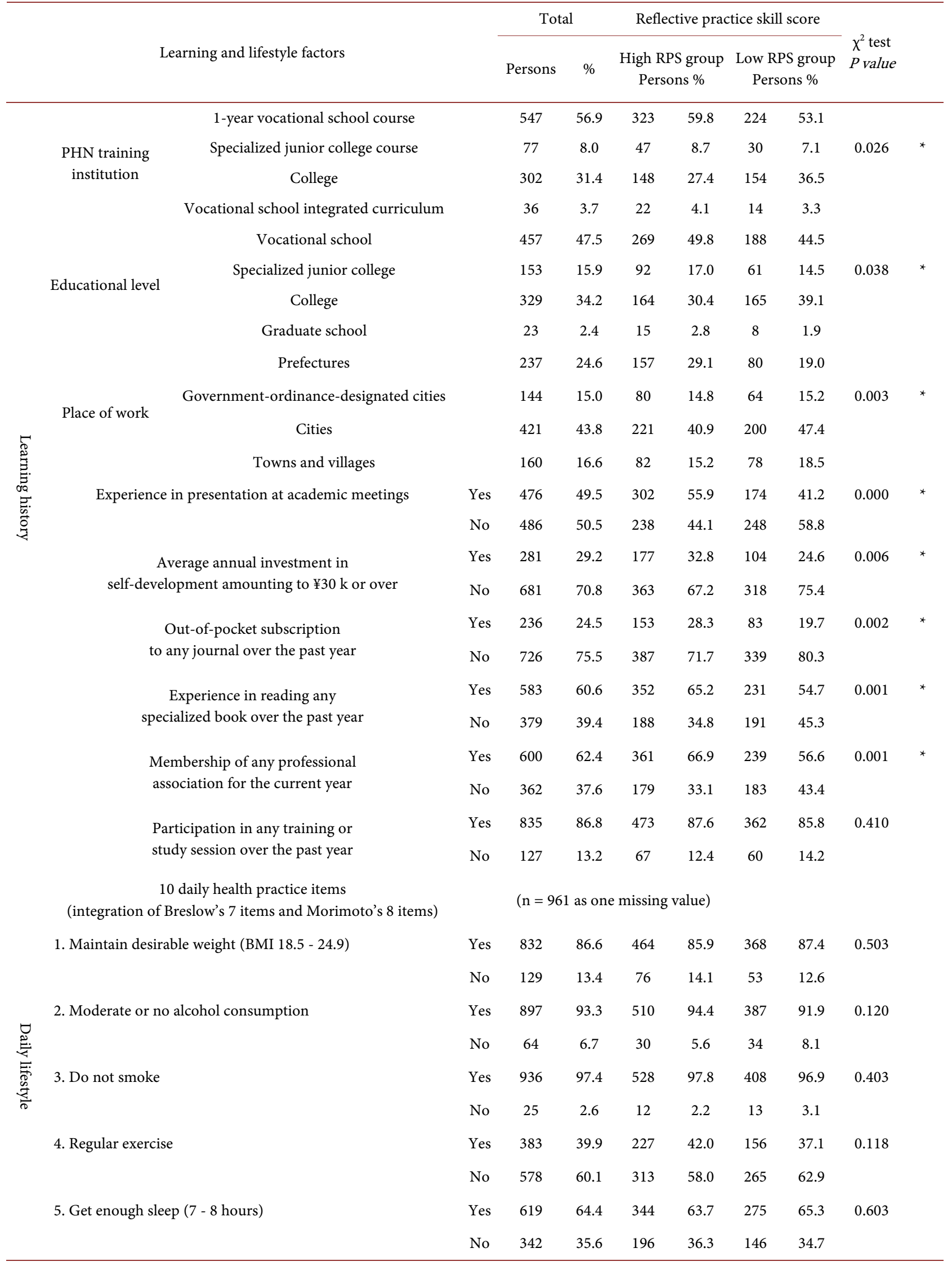




\section{Continued}

$\begin{array}{lccccccccc}\text { 6. Do not eat between meals } & \text { Yes } & 177 & 18.4 & 101 & 18.7 & 76 & 18.1 & 0.796 \\ \text { 7. Have daily breakfast } & \text { No } & 784 & 81.6 & 439 & 81.3 & 345 & 81.9 & \\ & \text { Yes } & 894 & 93.0 & 507 & 93.9 & 387 & 91.9 & 0.235 \\ \text { 9. Do not work over 9 hours per day } & \text { No } & 67 & 7.0 & 33 & 6.1 & 34 & 8.1 & \\ & \text { Yes } & 468 & 48.7 & 269 & 49.8 & 199 & 47.3 & 0.433 \\ \text { 10. Do not feel much subjective stress } & \text { No } & 493 & 51.3 & 271 & 50.2 & 222 & 52.7 & & \\ & \text { Yes } & 409 & 42.6 & 227 & 42.0 & 182 & 43.2 & 0.710 \\ \text { 8. Balanced diet } & \text { No } & 552 & 57.4 & 313 & 58.0 & 239 & 56.8 & & * \\ & \text { Yes } & 854 & 88.9 & 491 & 90.9 & 363 & 86.2 & 0.021 & *\end{array}$

6 positive health practice items

(determined by researchers through consultations)

$\begin{array}{lcccccccccc}\text { 1. Active in adopting useful health information in daily lifestyle } & \text { Yes } & 906 & 94.2 & 520 & 96.3 & 386 & 91.5 & 0.002 & * \\ \text { 2. Usually cook food for myself and my family } & \text { No } & 56 & 5.8 & 20 & 3.7 & 36 & 8.5 & \\ & \text { Yes } & 827 & 86.0 & 478 & 88.5 & 349 & 82.7 & 0.010 & * \\ \text { 3. Try consciously to walk and use stairs } & \text { No } & 135 & 14.0 & 62 & 11.5 & 73 & 17.3 & \\ & \text { Yes } & 769 & 79.9 & 447 & 82.8 & 322 & 76.3 & 0.013 & * \\ \text { 4. Always take care not to catch a cold } & \text { No } & 193 & 20.1 & 93 & 17.2 & 100 & 23.7 & & \\ \text { 5. Properly regulate life rhythm } & \text { Yes } & 919 & 95.5 & 523 & 96.9 & 396 & 93.8 & 0.025 & * \\ & \text { No } & 43 & 4.5 & 17 & 3.1 & 26 & 6.2 & & \\ \text { 6. Remain sociable with enjoyment } & \text { Yes } & 865 & 89.9 & 491 & 90.9 & 374 & 88.6 & 0.240 & \\ & \text { No } & 97 & 10.1 & 49 & 9.1 & 48 & 11.4 & & \end{array}$

${ }^{*}$ The items associated with RPS $(P<0.05)$ were used logistic regression analysis as dependent variables.

Table 4. Logistic regression analysis to clarify learning and lifestyle factors associated with reflective practice skill of public health nurses.

\begin{tabular}{|c|c|c|c|c|c|}
\hline \multirow{2}{*}{$\begin{array}{l}\text { Learning and } \\
\text { lifestyle factors }\end{array}$} & \multirow{2}{*}{$\begin{array}{l}\text { Partial } \\
\text { regression } \\
\text { coefficient }\end{array}$} & \multirow{2}{*}{$\begin{array}{c}\text { Significance } \\
\text { probability }\end{array}$} & \multirow{2}{*}{$\begin{array}{l}\text { Odds } \\
\text { ratio }\end{array}$} & \multicolumn{2}{|c|}{$\begin{array}{c}95 \% \text { Confidence } \\
\text { interval }\end{array}$} \\
\hline & & & & Lower & Upper \\
\hline $\begin{array}{l}\text { Remain sociable } \\
\text { with enjoyment } \\
\text { No 0/Yes } 1\end{array}$ & 0.828 & 0.000 & 2.290 & 1.484 & 3.533 \\
\hline $\begin{array}{l}\text { Active in adopting useful } \\
\text { health information } \\
\text { in daily lifestyle No } 0 / \text { Yes } 1\end{array}$ & 0.764 & 0.010 & 2.148 & 1.197 & 3.854 \\
\hline $\begin{array}{l}\text { Experience in presentation } \\
\text { at academic meetings No } 0 / \text { Yes } 1\end{array}$ & 0.491 & 0.000 & 1.634 & 1.251 & 2.135 \\
\hline $\begin{array}{l}\text { Experience in reading any } \\
\text { specialized book over } \\
\text { past year No } 0 / \text { Yes } 1\end{array}$ & 0.385 & 0.005 & 1.470 & 1.123 & 1.924 \\
\hline $\begin{array}{l}\text { PHN training institution College or } \\
\text { vocational school integrated } \\
\text { curriculum } 0 / \text { One-year vocational } \\
\text { school or junior college course } 1\end{array}$ & 0.322 & 0.022 & 1.380 & 1.047 & 1.819 \\
\hline
\end{tabular}

Adjusted for years of experience, step-up procedures, stepwise, likelihood ratio. 
of experience. This indicates that RPS might not be the kind of skill that simply improves with length of experience in public health nursing activities. In other words, improving RPS might require something other than practical experience as a public health nurse. What might those other factors be?

\subsection{Characteristics of Learning/Lifestyle Factors Related to Reflective Practice Skill}

(1) Commitment to positive health and balanced input/output

The factors that contributed to the higher RPS with an odds ratio of 2 or over were all related to positive health practice, namely those who "Remain sociable" or are "Active in adopting useful health information in daily lifestyle". Sociable public health nurses who take in useful health information are readily seen as being highly committed to positive health and enjoying interaction with the outside world, in terms of both input and output. Thus, a positive professionalism towards health promotion and affluence in human qualities appear to be closely related to higher RPS levels.

(2) Competency to drive activities for publication of results through continuing professional development

It was found that two learning history factors contributed to higher RPS with an odds ratio of about 1.5 - 1.6: "Experience in presentation at academic meetings" and "Experience in reading any specialized book over the past year". Thus, higher RPS levels are attained by those who continue their professional development by reading specialized books on a daily basis, run the PDCA cycle in their public health nursing activities, assess the results and present them at academic meetings. Thus, continuing professional development, as well as the competency to drive public health nursing activities based thereon towards the goal of publishing the results, can help improve the level of RPS.

(3) Adequate practical onsite training in a graduate course for PHN education

Other learning history factors contributed to higher RPS with an odds ratio of about 1.4: "PHN education in one-year vocational school or junior college course". The result indicates that the RPS level is higher among those who have received one-year institutional education with adequate time allocated to lectures, exercise and practical onsite training on public health nursing. In the 14-year period from 1997, when PHN education was integrated with nursing education in all colleges, the development of practical skills among public health nurses was seriously undermined by the double-counting of credits, for example [12]. Although such issues are now being addressed, our findings indicate the need for adequate education of public health nurses through a graduate course or one-year specialized graduate course.

\subsection{Limits of Study and Future Challenges}

Our study found: 1) that RPS among Japanese public health nurses is limited in that it does not help them develop action plans; 2) that RPS is not related to the years of practical experience as PHN; and 3) that higher RPS is related to some learning history and daily lifestyle factors. However, this study only succeeded in 
considering RPS from a limited number of aspects. Further literature study and research are needed to identify additional factors required for upgrading skills.

Going forward, we will need to consider how to accumulate learning on a daily basis and how to include positive health practice in PHN education, in connection with exploring the curriculum and method of training to improve the practical competence of PHNs.

\section{Acknowledgements}

We sincerely thank all public health nurses who participated in the survey.

This study was subsidized by JSPS Scientific Research Grant \#JP25671016.

We have no conflict of interest to report on our relationships with any specific entity.

\section{References}

[1] Schön, D.A. (1984) The Reflective Practitioner: How Professionals Think in Action. Basic Books, Inc., New York.

[2] Burns, S. and Bulman, C. (2000) Reflective Practice in Nursing: The Growth of the Professional Practitioner. 2nd Edition, Blackwell, Oxford.

[3] Ueda, N. and Miyazaki, M. (2010) Review of Literature on Reflection by Nursing Practitioner. Journal of Chiba Academy of Nursing Science, 16, 61-68. (In Japanese)

[4] Koide, K., Okamoto, R., Nekoda, Y. and Okada, M. (2015) Effect on Public Health Nurses of a Reflection-Based Health Guidance Skills Improvement Program. Journal of Japan Academy of Community Health Nursing, 17, 4-13. (In Japanese)

[5] Dewey, J. (1998) Experience and Education. 60th Edition, Kappa Delta Pi, Indianapolis.

[6] Gibbs, G. (1998) Learning by Doing: A Guide to Teaching and Learning Methods. Oxford Brooks University, Oxford.

[7] Saeki, K., Izumi, H., Uza, M. and Murashima, S. (2007) Factors Associated with the Professional Competencies of Public Health Nurses Employed by Local Government Agencies in Japan. Public Health Nursing, 24, 449-457. https://doi.org/10.1111/j.1525-1446.2007.00655.x

[8] Okamoto, R., Shiomi, M., Iwamoto, S., Hatono, Y., Chiba, Y., et al. (2008) Relationship of Experience and the Place of Work to the Level of Competency among Public Health Nurses in Japan. Japan Journal of Nursing Science, 5, 51-59. https://doi.org/10.1111/j.1742-7924.2008.00101.x

[9] Saeki, K., Izumi, H., Uza, M. and Takasaki, H. (2003) Development of a Way to Measure the Practical Competence of Public Health Nurses. Journal of Japan Academy of Community Health Nursing, 6, 32-39. (In Japanese)

[10] Belloc, N.B. and Breslow, L. (1972) Relationship of Physical Health Status and Health Practices. Preventive Medicine, 1, 409-421. https://doi.org/10.1016/0091-7435(72)90014-X

[11] Hagihara, A. and Morimoto, K. (1991) Personal Health Practices and Attitudes toward Nonsmokers' Legal Rights in Japan. Social Science \& Medicine, 33, 717-721. https://doi.org/10.1016/0277-9536(91)90026-9

[12] Murashima, S. (2010) Evaluation of Public Health Nursing Education: The Revision of Act on Public Health Nurses, Midwives and Nurses, and the Prospect of Public Health Nursing Education [Series 1]. Japanese Journal of Public Health, 57, 843847. (In Japanese) 
Submit or recommend next manuscript to SCIRP and we will provide best service for you:

Accepting pre-submission inquiries through Email, Facebook, LinkedIn, Twitter, etc. A wide selection of journals (inclusive of 9 subjects, more than 200 journals)

Providing 24-hour high-quality service

User-friendly online submission system

Fair and swift peer-review system

Efficient typesetting and proofreading procedure

Display of the result of downloads and visits, as well as the number of cited articles Maximum dissemination of your research work

Submit your manuscript at: http://papersubmission.scirp.org/

Or contact ojn@scirp.org 